\title{
Expenditures and receipts in state and local government finances: Reply*
}

\author{
MICHAEL L. MARLOW \\ U.S. Department of Treasury, Washington, DC 20220
}

NEELA MANAGE

Department of Economics, Florida Atlantic University, Boca Raton, FL 33431

Chowdhury (1988) adopts an alternative technique to test for causality between expenditures and receipts of state and local governments and claims that he obtains results that are different from those reported in our 1987 paper (Marlow and Manage, 1987). We disagree with many of his criticisms. In this reply, we argue that he misinterprets our results and policy implications and that his results are really not much different from ours; in fact, sometimes his results provide stronger support of our hypothesis.

\section{Optimal lag length}

Chowdhury criticizes our estimation procedure which utilizes symmetric lags from two to five periods as arbitrary. We make two points. One, we did not arbitrarily choose a single lag structure but analyzed the causal patterns over a relatively long range (up to five years). In the univariate and multivariate equations estimated by Chowdhury, the lag length which minimizes the Final Prediction Error (FPE) is selected by varying the lag length from $1, \ldots, n$ (where $\mathrm{n}=5$ in Chowdhury's paper). However, if the selected lag length equals $\mathrm{n}$ or is very close to $\mathrm{n}$, the literature suggests that the search of lag length be extended beyond $\mathrm{n}$ in order to determine if the optimal lag is greater than $\mathrm{n}$. In the regressions with local government revenues as the dependent variable, Chowdhury selects a four period lag. However, lag lengths exceeding five periods are 'arbitrarily' not examined to check if the FPE can be lowered by including lags greater than five. While Chowdhury claims to use the FPE criterion to avoid arbitrariness, his analysis should also include these checks for optimal

\footnotetext{
* The views expressed are those of the authors alone and do not necessarily represent those of the U.S. Department of Treasury.
} 
lag length. He justifies his choice of $n=5$ by using the rationale provided by Blackley (1986). We argue that our choice of restricting the lag lengths up to five periods is also based on similar reasoning and is not any more arbitrary than his method. Ram (1988) argues ' . . the experimental evidence provided by Guilkey and Salemi (1982) seems important enough to justify the use of preassigned lag lengths in the vicinity of what gave good results in their experiments.'

Two, with respect to symmetric lags, Chowdhury argues that they may result in overspecification or underspecification of the lag length and thereby result in either inefficient or biased estimates. In order to determine whether this is true, we attempted to compare our results with those reported by Chowdhury. However, there appears to exist a discrepancy between the lag lengths in three of the four regressions (Chowdhury, Table 4), and the reader is left to wonder if this comment is based on the lag forms reported in Table 2 or Table 4. For example, in his regression with state expenditure as the dependent variable, it is not clear if a $(1,3)$ lag (i.e., the RHS of the equation includes a one period lag for expenditures and three lagged values for receipts) or a $(1,4)$ lag structure is selected. He finds a unidirectional causal relation between state revenues and expenditures which is the same result we obtained when we used $(3,3)$ and $(4,4)$ lag structures. In fact, in seven of the eight bivariate equations we estimated, we obtain the same result as Chowdhury. Accordingly, we suggest that our use of symmetrical lags does not pose serious problems.

\section{Serial correlation}

Contrary to Chowdhury's criticism, we transformed the variables into their natural logarithms. The diagnostic tests we used to check for serial correlation consisted of estimating autoregressions on the residuals obtained from the estimated regressions. Similar diagnostic checks have been used by other researchers (Mehra, 1979; Williams et al., 1976; and Manage and Marlow, 1986). While one may argue that Chowdhury's point on the determination of trendstationarity and difference-stationarity is interesting, we argue that use of one approach over the other is more subjective than objective. Moreover, given the similarity in our results, we find it difficult to claim that Chowdhury's approach is either superior or necessary for the correct transformation of our data set.

\section{Results at the local level of government}

Chowdhury argues that he obtains different results at the local level of govern- 
ment. We consider his comparison incorrect and disagree with his argument that the level of aggregation exerts no potential impact on the local government results. For each bivariate equation, Chowdhury determines the lag length for the lagged dependent variable on the RHS and for the independent variable. He determined four lag lengths for the local level of government since he estimates two bivariate equations (see his Table 4) - one with expenditures and one with receipts as the dependent variable. Of these four, the length of three lags is two periods or less and the fourth lag equals three periods (Table 4). On the basis of these lags, he finds a feedback relation between expenditures and receipts. However, it is important to note that these interactions are observed for very short lag lengths. For the shortest lag structure (two periods) used in our study (which is close to the lag structure derived on the basis of the FPE criterion), we found that revenues cause expenditures, but expenditures do not cause revenues. Apparently, Chowdhury, by ignoring our results for the shortest lag structure, incorrectly restricts his comparison by considering only the longer lags where we do not detect causality. We observed at the shortest lag structure, ' $\ldots$ the one case where significant causality is observed lends some empirical support for the hypothesis that tax receipts support spending' (p. 251). Contrary to Chowdhury's claim, we are not arguing that local expenditures and revenues are independent of one another. Since we observed causality at the shorter lag, we argue that we need to be concerned about these interactions.

We disagree with Chowdhury's claim that our results for the longer lag structures can be attributed only to our methodology and are in no way influenced by aggregation problems. We feel that this claim is naive. Given the many diverse constraints affecting the financing of the myriad of local governments, it is difficult to argue that each locality is just another 'apple' in the barrel. Rather, the barrel is probably loaded with many apples, oranges, bananas .... Given these data problems, we argue that policy implications stemming from our results at the local level of government should require much scrutiny. In effect, this is just another application of the well-known aggregation problem in macroeconomics.

\section{Conclusion}

It is worth repeating that causality testing is a very complex task. The diversity of views on interpreting the definition of causality and on the methods for testing causality highlight this issue. In our study, we cite an excellent article which provides a detailed critique of various problems associated with causality tests (see Conway, et al., 1984). It would appear that Chowdhury's comment draws very strong conclusions and fails to consider some of the complex theoretical 
issues regarding causality tests as well as important data problems pertaining to state and local governments. Moreover, we find it somewhat curious that, given the strong similarities in our two studies, Chowdhury prefers to dwell on the mechanics of an alternative technique rather than concentrate on the fact that his alternative technique yields supporting results to our 1987 paper on the tax-spend hypothesis.

\section{References}

Blackley, P.R. (1986). Causality between revenues and expenditures and the size of the federal budget. Public Finance Quarterly 14: 139-156.

Chowdhury, A.R. (1988). Expenditures and receipts in state and local government finances: Comment. Public Choice 59: 277-285.

Conway, R.K., Swamy, P.A.V.B., Yanagida, J.F., and Muehln, P. von zur. (1984). The impossibility of causality testing. Agricultural Economics Research 36 (Summer): 1-19.

Guilkey, D.K., and Salemi, M.K. (1982). Small sample properties of three tests for Granger-causal ordering a bivariate stochastic process. Review of Economics and Statistics 64: 668-680.

Manage, N., and Marlow, M.L. (1986). The causal relation between federal expenditures and receipts. Southern Economic Journal 52 (January): 617-629.

Marlow, M.L., and Manage, N. (1987). Expenditures and receipts: Testing for causality in state and local government finances. Public Choice 53: 243-255.

Mehra, Y. (1977). Money wages, prices, and causality. Journal of Political Economy 85: $1227-1244$.

Ram, R. (1988). Additional evidence on causality between government revenue and government expenditure. Southern Economic Journal 54: 763-769.

Williams, D., Goodhart, C.A.E., and Gowland, D.H. (1976). Money, income and causality. American Economic Review 66: 417-423. 